\title{
Performance of Green Aggregate Produced by Recycling Demolition Construction Wastes (Case Study of Tanta City)
}

\author{
Alaa El-Din M. Sharkawi', Slah El-Din M. Almofty², Eng. Shady M. Abbass ${ }^{1}$ \\ ${ }^{1}$ Department of Structural Engineering, Faculty of Engineering, Tanta University, Tanta, Egypt \\ ${ }^{2}$ Department of Mining, Petroleum and Metallurgical Engineering, Faculty of Engineering, Cairo University, Giza, \\ Egypt \\ Email: amsharka@hotmail.com,shady_abbass2020@yahoo.com
}

Received 30 December 2015; accepted 19 February 2016; published 22 February 2016

Copyright (C) 2016 by authors and Scientific Research Publishing Inc.

This work is licensed under the Creative Commons Attribution International License (CC BY). http://creativecommons.org/licenses/by/4.0/

(c) (i) Open Access

\begin{abstract}
Egypt has a high attitude in construction and demolition waste (CDW) amounts causing a negative impact on the environment. The use of such waste for infrastructures applications can be useful for each environment and in addition an economic benefit to it in the construction. This study explores the possibility of replacing natural coarse aggregate with recycled concrete construction and demolition waste aggregate for general purpose concrete (i.e. plain concrete and low strength structural concrete). Different samples of CDW were extracted from different demolition sites and landfill locations around Tanta city area for the experimental investigation. CDW was crushed with all its hard constituents (e.g. concrete, brick etc.) found in the landfill. Coarse size crushed CDW was used as a coarse aggregate for concrete. Main characteristics of CDW aggregate determined in addition to the main properties of concrete which was made using this aggregate were measured. The results showed that the CDW could be transformed into recycled concrete aggregate leading to reduction in the concrete compressive strength ranged from $37 \%$ to $62 \%$ depending on the type of the CDW constituents.
\end{abstract}

\section{Keywords}

Concrete, Demolition, Recycling Aggregate, Recycling, Compressive Strength

\section{Introduction}

Generally, construction makes a considerable environmental impact through extraction of its raw materials. The use of excessive energy in production processes and production of accumulated byproduct waste are sources for 
damage to environment and health in different phases of the life cycle of hazardous components. The disposal of CDW has become a major concern in recent years, especially in developing countries. Some building owners, waste haulers and demolition contractors are disposing of this waste illegally, in open landfills, in order to avoid transportation costs at waste disposal facilities. As major a hazardous, construction and demolition waste is defined as the solid waste generated by the construction, remodeling, renovation, repair, alteration or demolition of residential, commercial, government or institutional buildings, industrial, commercial facilities and infrastructures such as roads, bridges, dams, tunnels, railways and airports. Egypt is one of the main countries which has huge surge in construction and demolition waste (CDW) quantities harmfully affecting the environment. The approximate amount of construction and demolition waste (CDW) in Egypt is 4.0 million tons annually [1], while the only current method of managing such waste is through disposal in landfills causing large deposits of CDW. Despite of many researches for studying the feasibility of recycling construction demolition wastes in the production of construction materials, no such local integrated results are available for application. On the other hand, using the recycled CDW instead of the rapidly diminishing natural resources provides essence of sustainable development due to the critical shortage of these resources (e.g. aggregate materials).

This research aims to explore various possible structural applications of selected samples of the local construction demolition wastes in order to increase the waste recycling opportunity with greater added value. This exploratory study is an introduction for comprehensive program to provide practical opportunities for the CDW recycling in Egypt as a sustainable resource of environment-friendly applications as well as a reference for current studies for preparing code of practice for CDW quality standards. On the other hand, such researches provide trust on using such recycled materials in several infrastructural applications.

\section{Previous Work}

In Egypt, recycled CDW can be used as an alternative of the natural aggregate for concrete and infrastructure applications to provide environment friendly solution for their huge landfills and to reduce the abuse of natural aggregate resources. Providing such sustainable recycled resource of aggregate preserves the natural resources for longer life span as well as reduces their demand. The use of recycled CDW in construction had started since the end of World War II by using a demolished concrete pavement as recycled aggregate in stabilizing the base course for road construction [2]. The major materials found in CDW at Egypt are concrete, bricks, sand, mortar and tile residues in which concrete represents up to half of the total waste weight [3]. Weigh et al. [4] discussed the possibility to replace natural coarse aggregate (NA) with recycled concrete aggregate (RCA) in structural concrete. A total of 50 concrete mixes forming eight groups were designed to study the effect of recycled coarse aggregates quality/content, cement dosage, use of super plasticizer and silica fume. The results showed that the concrete rubble could be transformed into useful recycled aggregate and used in concrete production with properties suitable for most structural concrete applications in Egypt. A significant reduction in the properties of recycled aggregate concrete (RAC) made of 100\% RCA was seen when compared to natural aggregate concrete (NAC), while the properties of RAC made of a blend of 75\% NA and 25\% RCA showed no significant change in concrete properties. The suitability of returned concrete aggregate for concrete applications had been investigated by many researchers. It was found that replacing virgin aggregates with returned concrete aggregate had resulted in $10 \%$ - 30\% reductions in compressive strength, with the least impact being found in mixes that only include recycled coarse aggregates.

\section{Research Objectives}

The main objectives of this research are to explore the opportunities of using CDW for various infrastructure applications. Therefore the following points are investigated:

1) The main characteristics of commonly recycled locally available construction and demolition waste (CDW) as an aggregate.

2) The performance of concrete made of recycled CDW coarse aggregate versus that made using natural aggregate. Fine recycled aggregate was not considered for the production of recycled aggregate concrete (RAC) because its application in structural concrete is generally not recommended [5].

This research has a vital effect on the production of sustainable materials for infrastructure applications and protection of the local environment. In order to accomplish the aim of the exploratory study, an investigation was undertaken into the properties of CDW collected from one of the main landfills in Tanta city-Egypt as a targeted area for further extended research work. 


\section{Experimental Program-Selecting the Recycled CDW Samples}

Four samples (i.e. A, B, C and D) of construction and demolition wastes (CDW) were selected-visually-from four different main landfill areas at Tanta city as shown in Figure 1. Each sample had $300 \mathrm{~kg}$ average weight to represent the most common types of such wastes. Samples had been cleaned from harmful material to concrete or fragile substances (i.e. paper, plastics, textile, wood and glasses). The hard constituents of each sample of construction and demolition waste were classified, visually, and Table 1 presents the constituents ratio. Two approaches were considered in using the CDW as concrete aggregate; 1-using the classified constituents separately or 2-using the mixed constituents of each sample. Sample's constituents were crushed using hammer crusher. Recycled CDW coarse aggregate size $(4.75$ - $37.5 \mathrm{~mm})$ was sieved to be prepared to simulate the grading curve of the dolomite natural aggregate to be used as concrete aggregate. Natural dolomite crushed stone was used, as control concrete aggregate, for comparison with the crushed CDW. Natural sand was the only fine aggregate used in all concrete samples. Aforementioned process was used to recycle both CDW sample and some of its constituents. Figure 2 shows different phases for preparing recycled, crushing and sieved CDW.
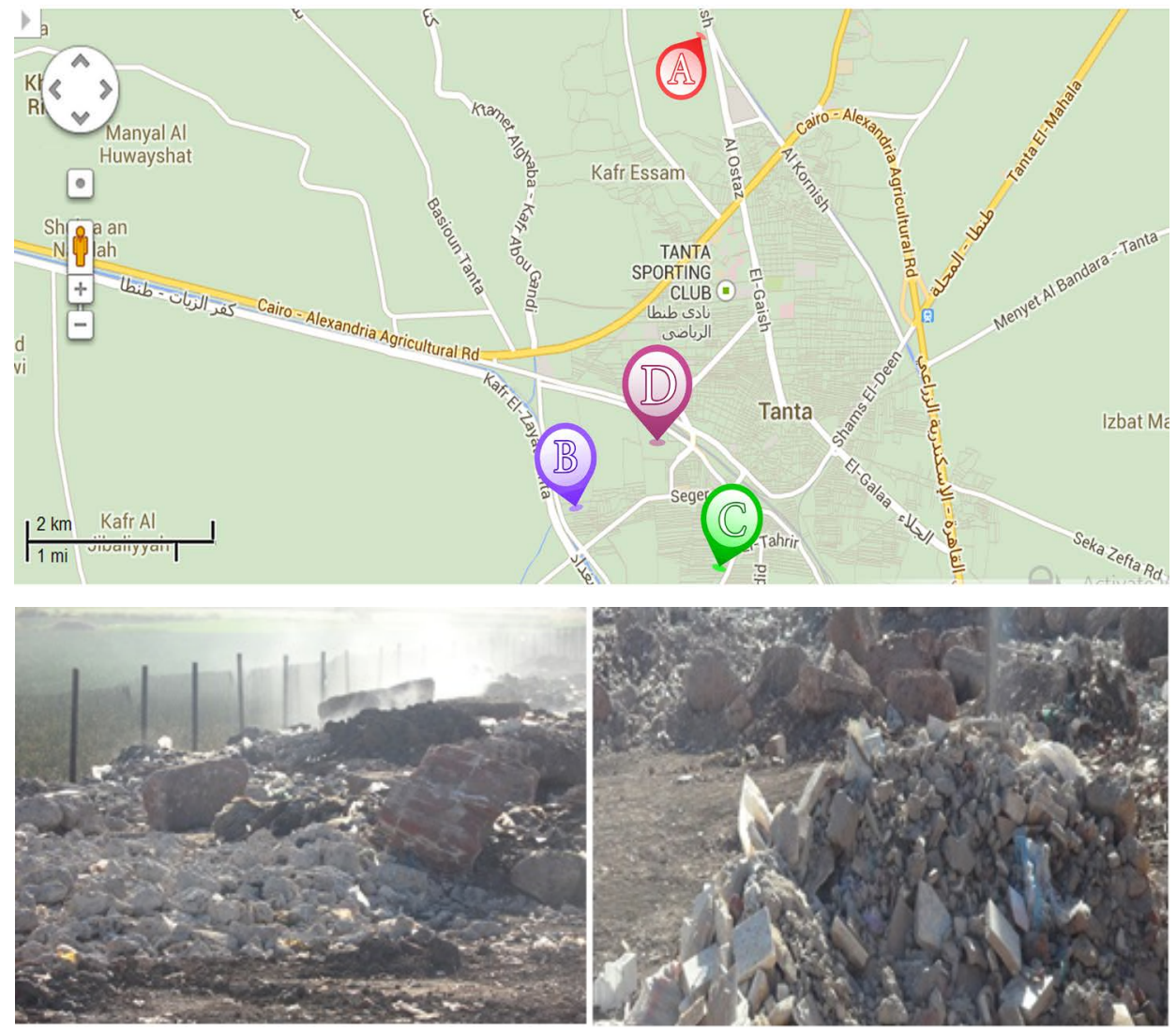

Figure 1. Map showing the sites that contain landfills and forms of recycled CDW.

Table 1. Approximate constituents ratios (by volume) of the selected construction and demolition wastes (CDW) samples extracted from four different locations.

\begin{tabular}{|c|c|c|c|c|}
\hline Sample ID & Red brick \% & Cement tiles \% & Concrete \% & White brick \% \\
\hline A & $30 \%$ & $20 \%$ & $40 \%$ & $10 \%$ \\
\hline B & $30 \%$ & $20 \%$ & $50 \%$ & - \\
\hline C & $45 \%$ & $30 \%$ & $25 \%$ & - \\
\hline D & $40 \%$ & $30 \%$ & $30 \%$ & - \\
\hline
\end{tabular}




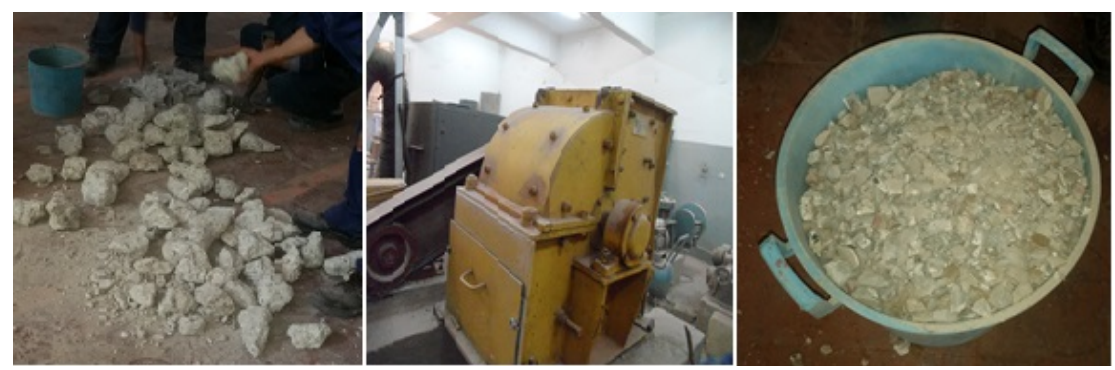

Figure 2. Different phases for preparing recycled, crushing and sieved CDW.

\section{Testing Recycled Concrete Aggregate}

Testing of the all aggregate types (i.e. recycled CDW and natural) was carried out as per Egyptian code of practice (ECP 203-2008, vol. 3) [6]. The following aggregate characteristics were measured during this research work:

1) Grading,

2) Specific gravity,

3) Bulk density,

4) Void ratio,

5) Water absorption,

6) Elongation index,

7) Angularity index,

8) Crushing value.

\section{Concrete Mixes and Testing}

CEM I $42.5 \mathrm{~N}$ was used in different concrete mixes and it was tested out as per the Egyptian Standard Specifications ESS 2421/2007. The used cement complied with the limits of ESS 4756-1/2009. Potable tap water was used for concrete mixing all through the study.

Seven concrete mixes - as shown in Table 2-had been designed to compare the properties of CDW with natural aggregate. Generally all mixes had constant cement content (300 kg/m ${ }^{3}$ ), water/cement ratio (0.55) and coarse/fine aggregate by volume ratios (2/1) as regularly used mix for all purpose concrete. Saturated surface dry (SSD) aggregate condition and absolute volume mix design method was used for all mixes. Table 2 shows different concrete mixes defining control mix and concrete mixes made of CWD as course aggregate. Control mix was made of dolomitic aggregate, while three mixes, RA, RB and RC, were made of mixed CDW extracted from sources A, B and C respectively. On the other hand, for mix R1-Con, crushed concrete, separated from recycled CDW of samples A, B, C and D were used as coarse aggregate. Similarly, for mix R2-Brick, crushed Red Brick, separated from recycled CDW of samples A, B, C and D, were used as coarse aggregate. For mix R3Tiles, crushed Tiles, separated from recycled CDW of samples A, B, C and D were used as coarse aggregate. Table 3 shows different concrete compressive strengths at 7 and 28 days of different mixes defining control mix, mix of concrete mixes from all sites, mix of cement tiles from all sites, mix of red brick from all sites, mix of all components in site (A), mix of all components in site (B) and mix of all components in site (C).

The following properties of concrete were selected to be measured:

- Bulk density of hardened concrete.

- Slump of fresh concrete.

- Compressive strength (age 7, 28 days).

- Indirect tensile strength (age 28 days).

\section{Results and Discussions}

\subsection{Recycled Concrete Aggregate}

Figure 3 shows the grading curves for different types of recycled CDW aggregate which were prepared to have grading curves close to the dolomite natural aggregate. Grading curves of all aggregate types are within the ECP 203 concrete aggregate limits, as shown in Figure 3. Figure 4 shows the relative properties of all types of the recycled aggregate with respect to the natural aggregate. 


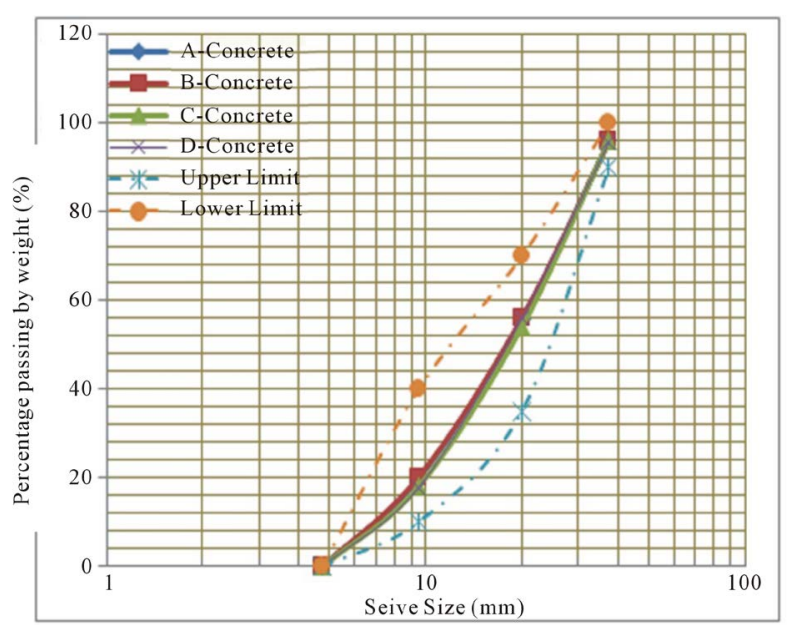

(a)

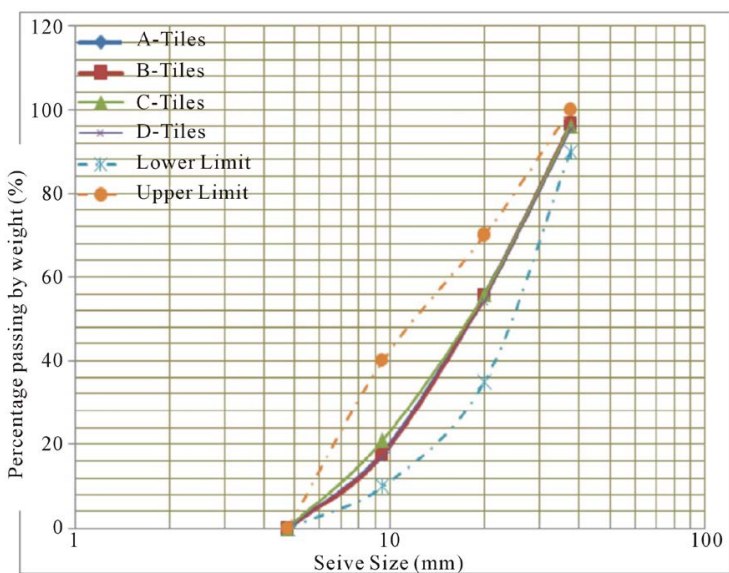

(b)

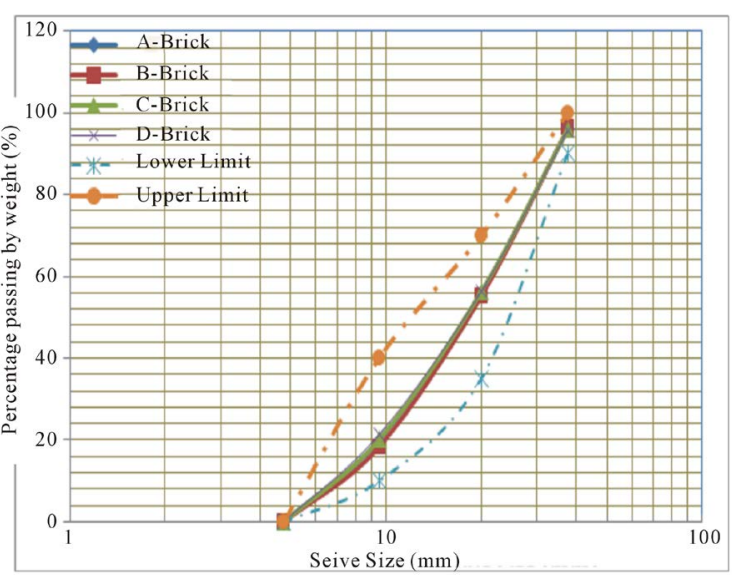

(c)

Figure 3. Grading curves for recycled aggregate with respect ECP limits. (a) Concrete in all sites; (b) Cement tiles in all sites; (c) Red brick in all sites.

Table 2. Shows different concrete mixes defining control mix (control) using dolomite and natural sand as a coarse.

\begin{tabular}{|c|c|c|c|c|c|c|c|c|}
\hline \multirow{2}{*}{$\begin{array}{l}\text { Constituents } / \mathrm{m}^{3} \\
\text { Concrete sample ID }\end{array}$} & \multicolumn{5}{|c|}{ Coarse aggregate source $\mathrm{kg}$} & \multirow{2}{*}{$\begin{array}{c}\text { Fine } \\
\text { aggregate kg }\end{array}$} & \multirow{2}{*}{ Water kg } & \multirow{2}{*}{$\begin{array}{c}\text { Cement } \\
\text { kg }\end{array}$} \\
\hline & Concrete & \multicolumn{2}{|c|}{ Cement tiles } & Red brick & Dolomite & & & \\
\hline Control & - & \multicolumn{2}{|c|}{-} & - & 1284 & 642 & 165 & 300 \\
\hline RA & 554 & \multicolumn{2}{|c|}{261} & 249 & - & 642 & 165 & 300 \\
\hline RB & 528 & \multicolumn{2}{|c|}{382} & 202 & - & 642 & 165 & 300 \\
\hline RC & 513 & \multicolumn{2}{|c|}{371} & 196 & - & 642 & 165 & 300 \\
\hline Constituents $/ \mathrm{m}^{3}$ & \multicolumn{5}{|c|}{ Coarse aggregate source kg } & \multirow{2}{*}{$\begin{array}{c}\text { Fine } \\
\text { aggregate kg }\end{array}$} & \multirow{2}{*}{ Water kg } & \multirow{2}{*}{$\begin{array}{c}\text { Cement } \\
\text { kg }\end{array}$} \\
\hline Concrete sample ID & A & B & C & D & Total & & & \\
\hline R1-Con & 294 & 280 & 268 & 268 & 1110 & 642 & 165 & 300 \\
\hline R2-Brick & 258 & 268 & 256 & 256 & 1038 & 642 & 165 & 300 \\
\hline R3-Tiles & 268 & 280 & 280 & 268 & 1096 & 642 & 165 & 300 \\
\hline
\end{tabular}




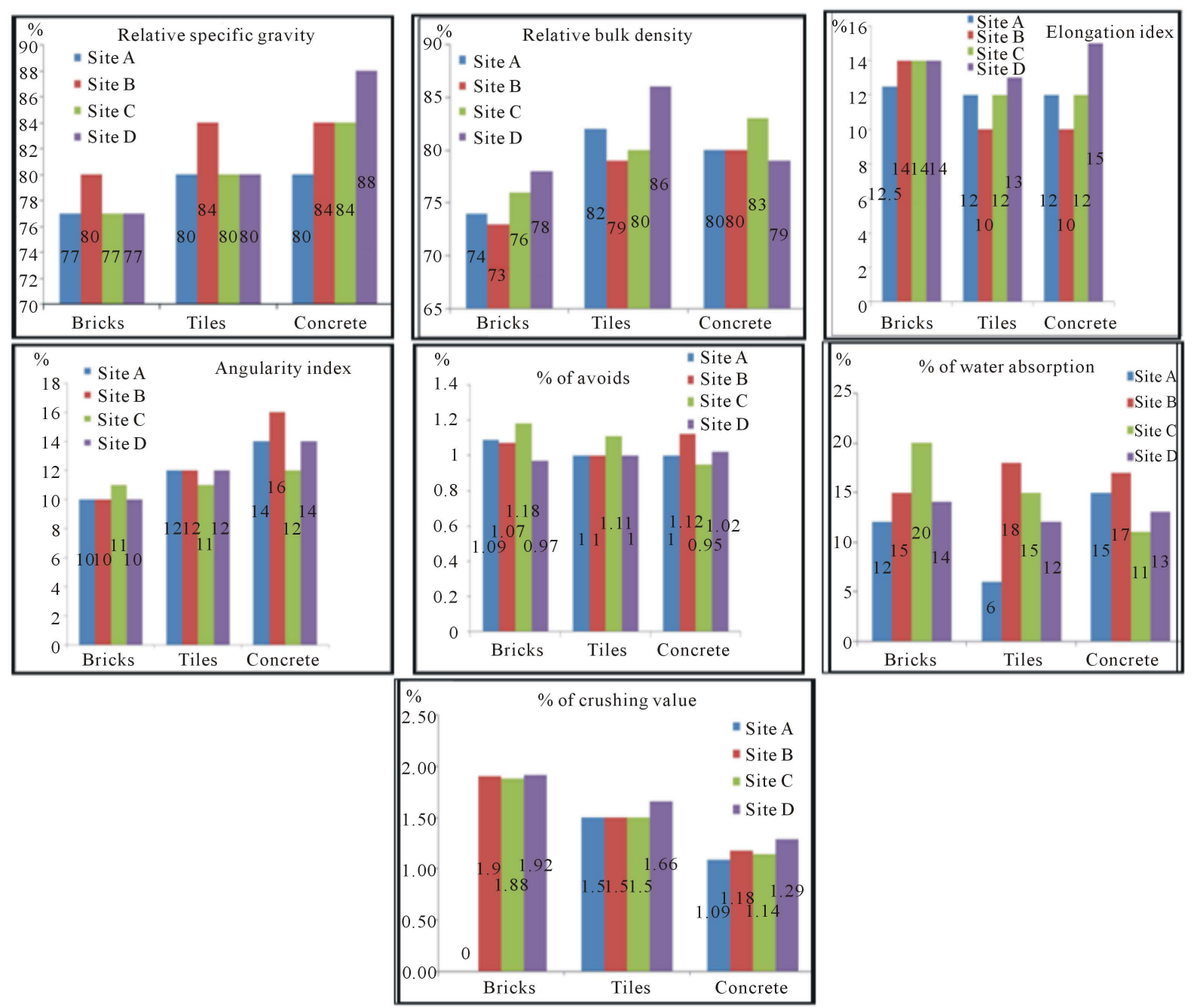

Figure 4. Shows the relative properties of all types of the recycled aggregate.

The relative specific gravity of recycled CDW was in the range of $77 \%-88 \%$ of the natural course aggregate, while the bulk density of recycled CDW was in the range of $73 \%$ - $86 \%$ of the natural course aggregate. The water absorption of recycled CDW coarse aggregate was higher than the dolomitic aggregate by $6 \%$ to $20 \%$. The crushing value of recycled CDW coarse aggregate was higher than the dolomitic aggregate by $1.09 \%$ to $1.92 \%$. The angularity index of recycled CDW coarse aggregate was higher than the dolomitic aggregate by 10 to $16 \%$. The elongation index of recycled CDW coarse aggregate was higher than the dolomitic aggregate by $10 \%$ to $15 \%$. The percentage of avoids of recycled CDW coarse aggregate was higher than the dolomitic aggregate by 0.95 to $1.18 \%$.

\subsection{Concrete Mixes}

Figures 5-7 show the properties of various concrete mixes which were made of different types of recycled CDW aggregate with respect to concrete made of natural aggregate properties. The maximum reduction of the compressive, indirect tensile, flexural and bond strengths were 37\%, 16\%, 26\% and 64\% respectively with using recycled CDW aggregate for making concrete with respect to natural concrete.

\subsection{Slump Test Results}

It is test done for measuring just coherence for the concrete mixture components and its result ranging between $(2.8-3.1) \mathrm{cm}$. 


\subsection{Compressive Test Result}

Table 3. Shows different concrete compressive strengths at 7 and 28 days.

\begin{tabular}{cccc}
\hline $\mathbf{N}$ & Simple code & Age (day) & Compressive (kg/cm) \\
\hline 1 & Control mix & 7 & 230 \\
2 & & 28 & 355 \\
3 & Site (A) & 7 & 183 \\
4 & & 28 & 224 \\
5 & Site (B) & 7 & 112 \\
6 & & 28 & 184 \\
7 & Site (C) & 7 & 93 \\
8 & & 28 & 134 \\
9 & Concrete & 7 & 132 \\
10 & Mix & 28 & 211 \\
11 & Brick & 7 & 104 \\
12 & Mix & 28 & 149 \\
13 & Tile & 7 & 117 \\
14 & Mix & 28 & 152 \\
\hline
\end{tabular}
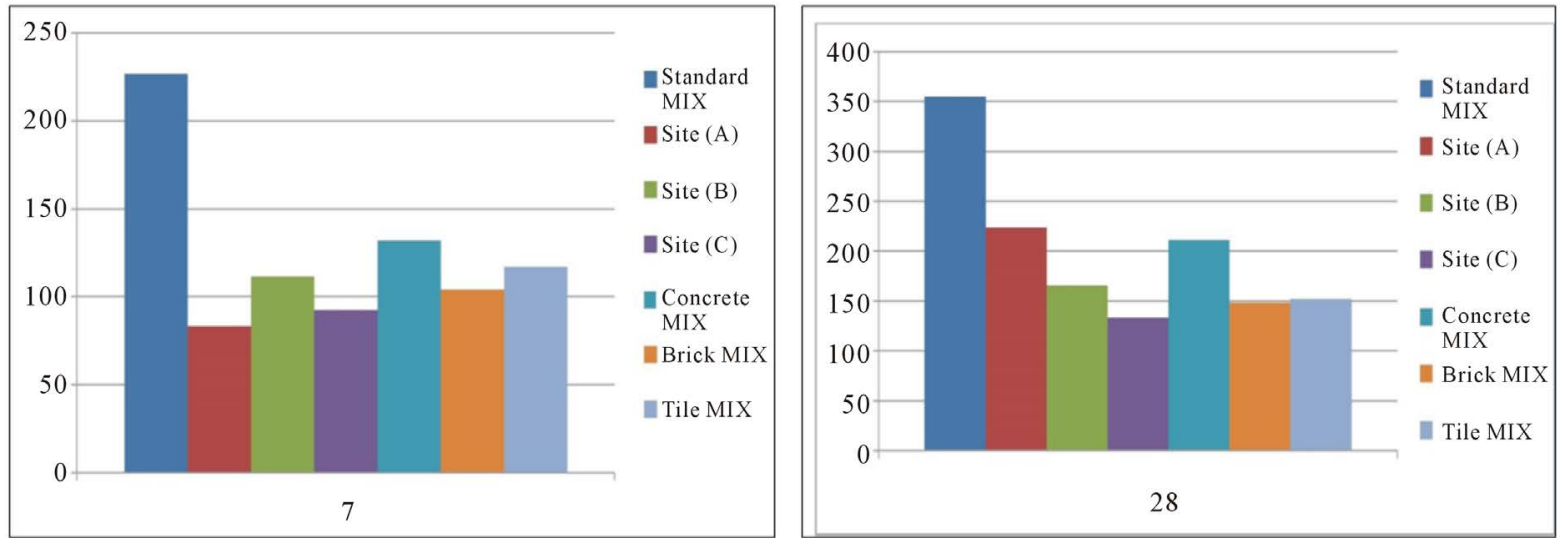

Figure 5. Shows the different compressive strengths at 7 and 28 days.

\subsection{The Results of the Test of Flexural Strengths}

\begin{tabular}{|c|c|}
\hline Sample name & Strengths $\mathrm{kg} / \mathrm{cm}^{2}$ \\
\hline Mix control & 48.36 \\
\hline Site (A) & 35.76 \\
\hline Site (B) & - \\
\hline Site (C) & 26.64 \\
\hline
\end{tabular}

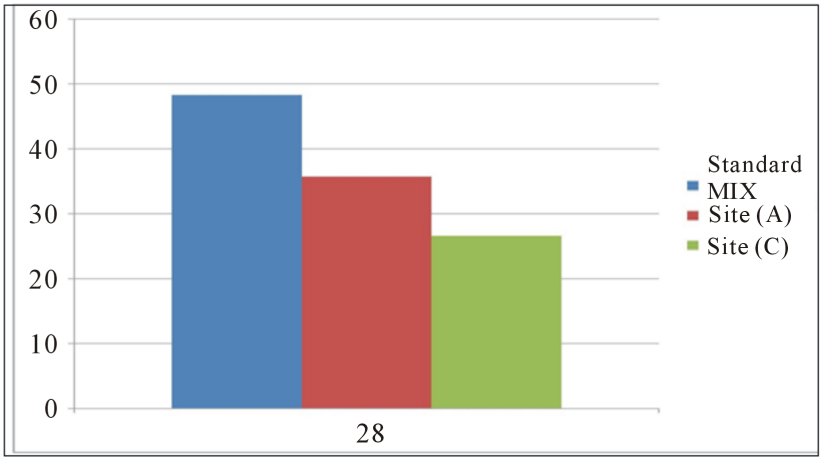

Figure 6. Shows the different flexural strengths at 28 days. 


\subsection{The Results of the Test of Indirect Tensile (Brazilian Tension)}

\begin{tabular}{|c|c|}
\hline & \\
\hline Sample name & Strengths $\mathrm{kg} / \mathrm{cm}^{2}$ \\
\hline Mix control & 21 \\
\hline Site (A) & 17.6 \\
\hline Site (B) & 13.5 \\
\hline Site (C) & 12.8 \\
\hline
\end{tabular}

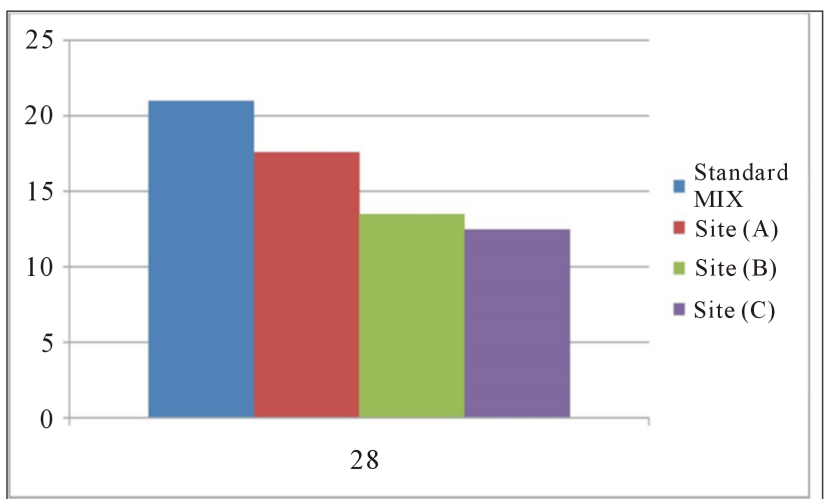

Figure 7. Shows the different indirect tensile strengths at 28 days.

\section{Conclusions}

Based on test results, the following conclusions are drawn:

1) Some properties of recycled concrete aggregate were lower than those required by Egyptian concrete code of practice such as crushing value, although it can be used for suitable low wearing/stress applications.

2) Construction and demolition waste (CDW) can be recycled to be used as concrete aggregate with properties suitable for infrastructure applications (e.g. pavement and sidewalk border). Few of the concrete mixes made of recycled CDW exceeded the lower strengths required for reinforced concrete (20 Mpa) where most of them exceeded the plain concrete strengths (17 Mpa).

3) In most of the concrete mixes made of recycled CDW aggregate, the regular ratios of natural aggregate concrete between both indirect tension and flexure strengths to compressive strength were fairly applied.

\section{Further Study}

Comprehensive study needs to be performed to investigate the following essential points to provide practical opportunity to recycle construction demolition wastes safely, providing economic added value which will cover the gap existing between providing promising research lab results for recycling residues and applying it in the main sources of the residues accordingly assure sustainable recycling process of such residues.

\section{References}

[1] Abou-Zeid, M.N., Shenouda, M.N., McCabe, S.L. and El-Tawil, F.A. (2004) Properties and Feasibility of Concrete made with Partial and Total Recycled Aggregates. 83rd Annual Meeting of the Transportation Research Board, Washington DC, Submitted

[2] Afsa, A. (2011) Performance and Properties of Concrete Elements Made with Recycled Aggregate. M.Sc. Dissertation, Menoufia University, Egypt.

[3] Hansen, T.C. and Narud, H. (1983) Strength of Recycled Concrete Made from Crushed Concrete Coarse Aggregate. Concrete International, 5, 79-83.

[4] Wagih, A., El-Karmoty, H., Ebid, M. and Okba, S.H. (2013) Recycled Construction and Demolition Concrete Waste as Aggregate for Structural Concrete. HBRC Journal, 9, 193-200. http://dx.doi.org/10.1016/j.hbrcj.2013.08.007

[5] Hendriks, C. and Janssen, G. (2001) Application of Construction and Demolition Waste. Heron, 46, 24-28.

[6] Ministry of Housing, Utilities \& Urban Development (2008) Egyptian Code of Practice for Design and Construction of Reinforced Concrete Structures (ECP 203-2008, Vol. 3). Ministry of Housing, Utilities \& Urban Development, Egypt. 